\title{
Implications of Policy and Legal Frameworks on Higher Education in Zambia
}

\author{
Eustarckio Kazonga ${ }^{a,{ }^{*}}$ \\ ${ }^{a}$ University of Lusaka, Zambia
}

\begin{abstract}
Policy and legal frameworks are enablers for the delivery of appropriate higher education (HE) in a country. Zambia is currently implementing reforms in the HE sub-sector within the context of the policy and legal frameworks. These frameworks have implications on the provision of HE. The objectives of the paper are to: identify the policy and legal frameworks for the HE sub-sector; and determine the implications of these frameworks on HE. A document analysis method was used for the study in order to determine the relevant policy and legal frameworks on HE. In particular, the analysis used qualitative data purposively collected from the following documents: (1) Educating Our Future: National Policy on Education of 1996; (2) Technical Education, Vocational and Entrepreneurship Training Policy of 1996; (3) Higher Education Act No. 4 of 2013 and Zambia Qualifications Authority Act No. 13 of 2011; (5) Higher Education Loans and Scholarships Act No. 31 of 2016; (6) Technical Education, Vocational and Entrepreneurship Training (TEVET) Act No. 13 of 1998 as amended by the TEVET Act No. 11 of 2005; and (7) selected Government Gazette notices. The study findings are that the higher education policy and legal frameworks implications are liberalization, quality assurance, appropriate responses to the national needs, flexibility in training programs, financing, partnerships, accountability, and relevance of training programs offered. The paper concludes that there are multiple policy and legal frameworks implications on HE in Zambia but key among these are registration and accreditation of learning programs, and development of quality assurance systems to address the multitude of the twenty-first century challenges and demands of excellence in HE.
\end{abstract}

Keywords: Higher Education, Implications, Policy Framework, Legal Framework, Zambia

\section{Introduction}

Policy and legal frameworks are enablers for the delivery of appropriate HE. Zambia is implementing a number of reforms in the HE sub-sector. The performance of Higher Education Institutions (HEIs) in meeting public expectations is influenced by various factors, all of which can be enhanced or even diminished by the policy and legal frameworks that shape institutional capabilities to respond, adapt and maintain flexibility in the face of change (Saint and Lao 2009; Saint 2009). At the end of the twentieth century the national policy frameworks for HEIs underwent substantial reforms. These reforms stem from the policy and supporting laws but it is claimed that lack of scholarly interest in the legal frameworks for HE is particularly evident in the case of sub-Saharan Africa (SSA) (Saint 2009). In the emerging global economy advanced human capital has become a crucial factor in economic development

*Corresponding author email addresses: ekazonga@yahoo.co.uk or e.kazonga@unilus.ac.zm. and a central component of a nation's competitive advantage (Trow 2005). Several countries, over-arching HE laws have recently been enacted for the higher education system replacing and repealing a collection of individual university Acts. Public university councils are being empowered to preside over university affairs without the need to obtain ministerial approval for their decisions. For example, these councils are empowered with freedom in the employment and dismissal of university staff, including senior management positions (Saint 2009). The shortage of research in the policy and legal frameworks for higher education is particularly evident in the case of sub-Saharan Africa (Ibid). Understanding these frameworks is becoming increasingly necessary in response to changing $\mathrm{HE}$ parameters of competition, market demand, and social expectations especially in developing countries like Zambia.

This paper uses two policy documents and various Acts of Parliament and then highlights their implications on HE. The paper identifies and analyses the implications of these policy and legal reforms on HE in Zambia. The objectives of the study were to: iden- 
tify the policy and legal frameworks for the HE sub-sector; and determine the implications of these frameworks on higher education institutions (HEIs).

Based on the Higher Education Act No. 4 of 2013, the concept of "higher education" as used in this paper means tertiary education leading to the qualification of a diploma, bachelor's degree, master's degree, or doctorate degree; and HEIs are those that provide higher education on a full-time, part-time, or distance learning basis.

Policies and supporting legislation are important facilitators for the provision of HE. Like any other product and service, HE in Zambia is supported and regulated by policies and laws. The HE specific policy and legal frameworks are detailed in the next two sections.

\section{Education Policy and Technical Education, Vocational and En- trepreneurship Training (TEVET) Policy}

These are the two major policy framework documents on HE in Zambia (i.e., Chapter 10 in the 1996 Education Policy and the 1996 Technical Education, Vocational and Entrepreneurship Training (TEVET) Policy. On the basis of these policy documents, reforms are currently being implemented in the sub-sector. There are 13 provisions in the policy documents and their implications are briefly discussed below.

\section{Government's Commitment}

Government strongly reaffirms the important role education plays in human capital development as the basis of all other development. It will act, therefore, as the overseer for enhancing the contribution of education and training to economic development and improved social cohesion. This entails that government is committed to human resource development through the provision of $\mathrm{HE}$ and training. HEIs are, therefore, expected to take advantage of this commitment to develop the necessary human capital for innovation and wealth creation.

\section{Liberalization}

The liberalization of educational provision entails major fundamental changes in institutional setups in HE. This policy measure has resulted in multiplicity of HEIs. Under a liberalized educational system, the right of private organizations, individuals, religious bodies, and local communities to establish and control their own HEIs is recognized and welcomed. Liberalization of educational provision allows those with resources to establish such institutions and to run them in accordance with their own principles but within the overall government policy and legal frameworks. Therefore, the private sector is being encouraged to participate in the provision of $\mathrm{HE}$ in the country as long as they meet the minimum set standards by the regulators such as the Higher Education Authority (HEA) and Zambia Qualifications Framework (ZAQA). In this way, liberalization will contribute to the expansion of educational opportunities while protecting the right of parents to send their children to HEIs of their own choice, be they public or private.

\section{Quality}

The policy provides for all learners to be facilitated in the attainment of the highest standards of learning through teaching of excellent quality learning programs. Quality is expected to be brought about by maximizing the efforts of all those responsible for the education of learners and by coordinating all the structures of the system so that centers of $\mathrm{HE}$, are places where effective teaching, learning and research take place and where the highest standards of achievement, in accordance with ability, are obtained by every student. This policy provision implies that there is need for greater emphasis on internal quality assurance and the encouragement of an institutional "Quality Culture" (Bogue 1998). HEIs are, therefore, required to develop their own internal quality assurance systems for provision of quality HE.

\section{Financing}

The policy on financing of higher education is that it will be on a shared basis between the Government, the institutions themselves, and students. The policy provides for the government to support students in HEIs in the form of loans that will be recovered during the students' subsequent working life. Students from all HEIs, both public and private would be eligible to apply for the loans. This provision has given birth to the Higher Education Loans and Scholarships Board as created by the Higher Education Loans and Scholarships Act No. 31 of 2016. This further implies that HEIs need to develop strategies for widening their financial resource base and diversifying their sources of revenue.

The policy makes a provision for financing of education and training to ensure that all institutions and persons providing TEVET whether formal or informal training have equal access to training funds provided that they deliver training in an acceptable manner. This implies that TEVET institutions can provide formal or informal training but they need to meet the minimum standards set by the regulator-TEVETA. 


\section{Partnerships}

Building on the principle of liberalization and on the creation of an enabling environment, the Zambian Government has committed itself to the policy that encourages and strengthens partnerships in HE development. This policy provision implies that public HEIs can enter into public-private partnerships (PPPs) when and if necessary. An HEI may enter into a PPP in accordance with the PublicPrivate Partnership Act No. 14 of 2009 (Educating Our Future: National Policy on Education of 1996).

\section{Accountability}

The policy acknowledges that there are many legitimate competing demands for resources in the country. The amount of money available for HE is limited. To ensure the best possible use of available resources and to allow for full public accountability, the Government has committed itself to ensuring that effective systems are in place at national, provincial, district, and institutional levels for evaluating the effectiveness and efficiency with which resources are used.

The policy demand for accountability is a clear assignment of responsibility for efficient use of resources to produce results and the mechanisms whereby this performance can be monitored (Saint and Lao 2009; Saint 2009). On balance, accountability mechanisms constitute feedback loops that enable decision makers at various levels of the HE system to receive information regarding its performance so that appropriate adjustments can be made in a timely manner. From this perspective, accountability mechanisms are a critical aspect of institutional responsiveness, and they are therefore included within the scope of institutional assessments/audits (Saint 2009).

The public HEIs are major recipients of government funds. Parliament every year appropriates public financial resources to these institutions in the national budget. The policy demands financial righteousness. The policy proposes a statutory requirement that the universities submit annual audited financial statements to the Minister of Higher Education for laying before Parliament. It is clear that proper financial accounting, however, does not automatically ensure that funds are being used effectively or that quality of HE is being protected. This implies that HEIs need to develop procedures and mechanisms for evaluating their activities. As semi- autonomous institutions, it is the responsibility and right of the HEIs themselves to establish these mechanisms, identify their own performance indicators, and conduct their own self-audits in the public accountability systems.

\section{Response to National Needs}

The policy indicates that if HEIs are to respond to national needs, they must know what those needs are. This implies that regular labor market surveys should be conducted in order to respond to these national needs. The implication of the policy is that for HEIs to be responsive to the needs of change-driven societies, they must be cognizant of "fitness for purpose" of their outputs (Varghese 2008).

\section{Relevance of Programs}

The relevance of training and programs should be ensured by extensive interaction between the HEIs and various sectors of the economy. This can be achieved by HEIs through linkages with the industry. These linkages can be established through interactions with professional bodies. For example, direct involvement in the institutions' activities by bodies such as the Employers' Federation, Zambia Association of Chambers of Commerce and Industry, government ministries and other organizations. These can assist in ensuring that the learning programs offered respond to the needs of the labor market.

\section{Program Flexibility}

The policy demands learning program flexibility, both in terms of the curriculum and delivery. The speed with which knowledge technological changes are taking place requires regular curriculum review in order to avoid preparing students for the past and not for the future. The concept of flexibility also implies flexible mode of delivery such as part-time and distance learning.

\section{Quality of Higher Education}

Quality is demanded in the provision of higher education. This demand implies that institutions must ensure that standards prescribed by regulators are strictly followed. Some of these standards are on the qualifications and experience of teaching staff, adequacy of physical facilities for learning, sufficiency of consumables, quality of libraries, laboratories and workshops as they have an impact on the quality of graduates from the HEIs. This provision implies that quality provision of HE, as guided by the regulators (Higher Education Authority [HEA], Zambia Qualifications Authority [ZAQA], and professional bodies] and the labor market, should be the point of focus for HEIs. 


\section{Establishment of the HEA}

The policy recognizes that the provision of higher education in the country is diverse as compounded by the multiplicity HE providers. The programs offered differ in scope, depth, and duration. The government proposed the establishment of the HEA, which has now been done. The implication of the establishment of the HEA is that coordination and regulation of all higher education will be achieved. Furthermore, the Government has now a body to advise it on the HE policy in the country.

\section{Entrepreneurship Development, Self-Employment and the Infor- mal Sector}

The Technical Education, Vocational and Entrepreneurship Training (TEVET) Policy emphasizes on entrepreneurship development, self-employment, and the informal sector. The policy covers training being conducted at all levels in both the formal and informal sectors. This implies incorporation of entrepreneurship in all TEVET programs offered and also provision of informal sector training. Skills and knowledge acquired in both formal and informal sectors are supposed to be appropriately recognized in the TEVET system.

\section{Coverage of All Types of Training}

The TEVET policy recognizes different categories of people in our society who are most likely to benefit the country from this training such as: (1) school leavers (i.e., Grade 7, Grade 9, and Grade 12); (2) employees in the formal sector; (3) entrepreneurs, both in the formal and informal sector; (4) the unemployed and underemployed including employees in the informal sector; (5) women; and (6) retrenchees.

The implications of this policy provision are that TEVET institutions are expected to ensure flexibility in their provision of training to take into account various categories of trainees. These can include flexible entry requirements and provision of different modes of training. It is imperative, therefore, that TEVET is designed to satisfy the demands of the labor market. There is therefore need to match the supply of skilled manpower and the demand of the labor market. In order for this to be done, this implies that the TEVET system should be designed in such a way that it is highly responsive to the demands of the employment pattern in the economy. TEVETA is expected to enhance the capacities of the education and training systems to develop curricula that provide skills useful to the labor market and those which would enable such graduates to enter the productive sector.

\section{The Legal Framework}

HE in Zambia is supported and regulated by a number of pieces of legislation, which include: Zambia Qualifications Authority (ZAQA) Act No. 13 of 2011; Higher Education Act No. 4 of 2013; Higher Education Loans and Scholarships No. 31 of 2016; Technical Education, Vocational and Entrepreneurship Training (TEVET) Act No. 13 of 1998 as amended by the TEVET Act No. 11 of 2005; and Government Gazette Notices.

\section{ZAQA Act No. 13 of 2011}

The Act empowers ZAQA to develop and implement a National Qualifications Framework for the classification, accreditation, publication and articulation of quality-assured national qualifications. According to Clause 4 (1) the objectives of the Framework are to:

- create a single integrated national framework for learning achievements;

- facilitate access to, and mobility and progression within, education, training and career paths;

- enhance the quality of education and training; and

- promote education, training and employment opportunities.

The implication of this provision is that HEIs need to fully understand the concept of a national qualifications framework particularly qualifications levels and level descriptors are they are part of standards in higher education. This further implies that curriculum development and assessment of students must have reference to the qualification levels and descriptors. Through this tool there will be national recognition of the qualifications offered by individual HEIs. In response to the need for a national qualifications framework, the ZAQA Gazette Notice No. 527 of 2016 dated 22 July 2016 in accordance with the provisions of the Zambia Qualifications Act No. 13 of 2011, articulates the Zambia Qualifications Framework (ZQF) qualification levels, level descriptors, and qualification outcomes. The ZQF Level Descriptors describe outcomes that cover the great majority of existing qualifications. However, the framework has the flexibility to accommodate diversity and innovation, and to accommodate new qualifications as the need for them arises. Functional competence and standard duration of learning programs are also given. For example, Level 7 - Bachelor's degree will take 4-to-7 years, Level 8 - Postgraduate Diploma will take 1 year after Level 7, Level 9 - Master's degree will take 1.5-to-2 years after Level 7, and Level 10 - Doctorate will take at least 3 years.

The implications of the gazette notice are that qualifications offered by a HEI need to be standardized and nationally recognized 
and confirmed that they meet national standards. Therefore, it is necessary and imperative that training programs offered are accredited with the HEA and registered on the National Qualifications Framework (NQF) by ZAQA. Furthermore, the descriptors require that all higher education providers [both public and private] adhere to the published Level Descriptors in order to have their qualifications recognized by ZAQA. Level descriptors prescribe the learning outcomes of each qualification. The descriptors prescribed are competence-based and describe learning outcomes in terms of foundational, practical and reflexive competences for HEIs to implement.

\section{Higher Education Act No. 4 of 2013}

Among the functions of the Authority, Clause 6 of the Act provides for the (1) regulation of HEIs and coordination of the development of higher education; (2) promotion of quality assurance in higher education; (3) auditing of the quality assurance mechanisms of higher education; (4) restructuring and transforming HEIs and programs to be responsive to the human resource, economic and development needs of the country; (5) promotion of access of students to HEIs; and (6) designing and recommending an institutional quality assurance system for HEIs, and recommending to the Minister institutional quality assurance standards.

As a result of the liberalization of higher education, by April 2016, there were 19 registered private HEIs in the country. Fourteen of these were registered to provide both full time and open and distance learning delivery mode of learning. The implications of this are that all private HEIs must apply for registration with the HEA. Additionally, all HEIs (public and private) need to apply for accreditation of learning programs.

The HEA and the ZAQA are quality assurance bodies that will enhance of the quality of institutions and learning programs. Essentially, quality assurance systems aim to provide appropriate evidence to substantiate claims made about quality and so to enable key stakeholders to have confidence about the management of quality and the level of outcomes achieved in the HEIs. There is a general understanding that the aim is central to the culture and values of higher education and drives the motivation for continuous improvement (Dittrich 2014).

Clause 10 of the Act empowers the Authority, for purposes of ensuring compliance with the provisions of the Act, to establish an inspectorate unit of the Authority. In this regard an inspector may, for the purpose of enforcing the provisions of this Act, at any reasonable time, without prior notice, and on the authority of a warrant, enter any premises of a HEI that the inspector has reasonable grounds to believe is used by any person for the commission of an offence or contrary to the provisions of this Act. This implies that HEIs must strengthen their internal systems and to always be ready for the inspectors to comply with the provisions of the Act. Inspection should be understood as part of the external quality assurance mechanism in higher education. The most important part is development and implementation of internal quality assurance systems. The external quality assurance system will take into account the effectiveness of the developed internal quality assurance system.

Financial accountability is addressed in the Act through Clause 9, which specifically demands that a Council of a public HEI shall, in respect of every financial year, prepare or cause to be prepared, estimates of the income and expenditure of the Council and shall submit the estimates to the Minister at least four months before the commencement of the financial year for scrutiny and consolidation into the Ministry's estimates, before submission to the Ministry responsible for finance for approval. Furthermore, a public HEI shall cause to be kept proper books of accounts and other records relating to its accounts within ninety days of the expiry of the financial year, submit to the Minister a report concerning its activities during the financial year. The report shall include audited statements of income and expenditure and a statement of affairs or balance sheet. A public HEI shall submit to the Minister a report concerning its activities during the financial year. In turn, the Minister shall lay it before the National Assembly. The implications of these provisions are that HEIs develop good record-keeping systems, adhering to timeframe in the submission of the annual reports and ensuring that final financial statements are audited.

\section{Higher Education Loans and Scholarships Act No. 31 of 2016}

As part of addressing the issue of financing of HE, the Act establishes the Higher Education Loans and Scholarships Board; establishes the Higher Education Loans and Scholarships Fund; provides for the granting, administration, investment, payment and recovery of loans; provides for the administration and granting of scholarships; and facilitates the mobilization of financial resources for loans and scholarships. Clause 21 specifies that a student is eligible for consideration for a loan if the student is admitted to, or registered as a student at, a HEI within Zambia for a course of at least one academic year's duration; and satisfies such other conditions as the Minister may prescribe by statutory instrument. The Act, therefore, implies that HEIs must fully understand the guidelines regarding loans and scholarships so that students can be guided and made aware of this provision being available on competitive basis. 


\section{TEVET Act No. 13 of 1998 as amended by the TEVET (Amend- ment) Act No. 11 of 2005}

The TEVET Act No. 13 of 1998 created the Technical Education, Vocational and Entrepreneurship Training Authority (TEVETA) with the main functions of regulating, monitoring, and coordinating technical education, vocational and entrepreneurship training in consultation with industry, employers, workers and other stakeholders. TEVETA is specifically charged with a responsibility of collecting, managing and disseminating labor market information relating to technical education, vocational and entrepreneurship training; determining equivalencies of local and foreign qualifications; and accrediting and registering trainers, examiners, and assessors. These legal provisions imply that TEVETA is expected to collect labor market information, which may be used as part of role materials in the development and review of national curricula.

The TEVET Act No. 11 of 2005 establishes the Technical Education, Vocational and Entrepreneurship Training Fund administered and managed by TEVETA. This is meant for funding skills development for better productivity and innovation in the country.

\section{Conclusion and Recommendations}

This paper has profiled the policy and legal frameworks for HE in Zambia and the implications of these frameworks on HE. The key implications are registration and accreditation of learning programmes, development and implementation of strong quality assurance systems, development of research partnerships between and among HEIs as they address the multitude of the twenty-first century challenges and demands of HE.

On the basis of the issues raised in this paper, it is recommended that the HEA and ZAQA develop internal quality assurance development capacities in HEIs to achieve the much needed excellence in HE as articulated in the policy and legal frameworks. Once this capacity is developed, quality assurance issues in HE will be internalised and in turn will reduce the work of the regulatory bodies. This, however, requires allocation of appropriate financial resources from the government to both HEA and ZAQA to enable them function as expected.

\section{References}

Bogue, E. Grady. 1998. "Quality Assurance in Higher Education: The Evolution of Systems and Design Ideals." New Directions for Institutional Research, 1998 (99): 7-18.
Bowen, Glenn A. 2009. "Document Analysis as Qualitative Research Method." Qualitative Research Journal 9 (2): 27-40. DOI: 10.3316/QRJ0902027.

Dittrich Karl. 2014. Preface." In The Concept of Excellence in Higher Education, by Manuela Brusoni et al. (pp. 5-6). ENQA Occasional Papers 20. Brussels: European Association for Quality Assurance in Higher Education.

Government of the Republic of Zambia. 1996a. Education Our Future: National Policy on Education. Lusaka: Ministry of Education.

Government of the Republic of Zambia. 1996b. Technical Education, Vocational and Entrepreneurship Training Policy. Lusaka: Ministry of Education.

Government of the Republic of Zambia. 1998. Technical Education, Vocational and Entrepreneurship Training (TEVET) Act (No. 13 of 1998). Lusaka: Government Printers.

Government of the Republic of Zambia. 2005. Technical Education, Vocational and Entrepreneurship Training (TEVET) (Amendment) Act (No.11 of 2005). Lusaka: Government Printers.

Government of the Republic of Zambia. 2009. Public-Private Partnership Act (No. 14 of 2009). Lusaka: Government Printers.

Government of the Republic of Zambia. 2011. Zambia Qualifications Authority Act (No. 13 of 2011). Lusaka: Government Printers.

Government of the Republic of Zambia. 2013. Higher Education Act (No. 4 of 2013). Lusaka: Government Printers.

Government of the Republic of Zambia. 2016. Higher Education Loans and Scholarships Act (No. 31 of 2016). Lusaka: Government Printers.

Saint, William. 2009. "Legal Frameworks for Higher. Education Governance in Sub-Saharan Africa." Higher Education Policy 22 (4): 523-550.

Saint, William, and Christine Lao. 2009. Legal Frameworks for Tertiary Education in Sub-Saharan Africa: The Quest for Institutional Responsiveness. Working Paper No. 175. Washington, DC: Africa Region Human Development Department.

Trow Martin. 2005. "On Mass Higher Education and Institutional Diversity." Paper read to a conference on Israeli Higher Education, organized by the United States-Israel Educational Foundation, Tel Aviv, 8 April 2003; and at the Samuel Neaman Institute for Advanced Studies in Science and Technology, Technion-Israel Institute of Technology, May 2003.

Varghese, N.V. 2008. "State, Markets, Faith and Proliferation of Private Higher Education in Africa." Paper presented at the 2008 Biennial Conference of the Association for the Development of Education in Africa. Paris: International Institute for Educational Planning, UNESCO. 
Excellence in Higher Education, Volumes 8 \& 9, Numbers 1 \& 2, December 2018, pp. 8-13 doi: 10.5195/ehe.2018.157 | http://ehe.pitt.edu 